\title{
O livro digital infantil: análise do livro-aplicativo pequenos grandes contos de verdade
}

\begin{abstract}
Alice Atsuko Matsuda ${ }^{1}$
Jaqueline Conte ${ }^{2}$

Resumo:

Este artigo tem como objetivo tecer considerações a respeito do livro digital interativo para crianças, suas características e potencial para a educação literária, tomando como objeto de estudo o livro-aplicativo Pequenos grandes contos de verdade, vencedor do Prêmio Jabuti, na categoria Infantil Digital, no ano de 2016. Primeiramente, apresentamos um apanhado geral do livro digital voltado ao público infantil e juvenil para, em seguida, descrever o livro digital ganhador do Prêmio Jabuti de 2016, analisando alguns aspectos de sua composição. Posteriormente, discutimos o uso dos aparelhos eletrônicos móveis, a sua materialidade e acesso, para, então, oferecermos algumas conclusões.

Palavras-chave: Livro digital interativo; Literatura infantil; Educação literária; Livroaplicativo; app-books.
\end{abstract}

\begin{abstract}
:
This paper considers interactive digital books for children, their characteristics and potential for literary education. The object of this study is the app-book Tiny Great True Stories, winner of Brazil's Jabuti Prize in 2016, in the category Digital for Children. First, we present an overview of digital books aimed at children and young people, and then describe the winning digital book of the Jabuti Prize 2016, analyzing some aspects of its composition. We then discuss the use of mobile electronic devices, their materiality and availability, and finally offer our conclusions.

Keywords: Interactive digital book; Children's literature; Literary education; Book-application; app-books.

${ }^{1}$ Doutorado em Letras - Estudos Literários - pela Universidade Estadual de Londrina (UEL) e, atualmente, desenvolve estágio Pós-Doutoral na Universidade de Coimbra, integrando o Grupo de Investigação em Materialidades da Literatura. É professor titular - Adjunto 4 - da Universidade Tecnológica Federal do Paraná-Câmpus Curitiba (UTFPR-Curitiba) e docente permanente do Programa de Pós-Graduação em Estudos de Linguagens (PPGEL).

${ }^{2}$ Mestranda do Programa de Pós-Graduação em Estudos de Linguagens (PPGEL), da Universidade Tecnológica Federal do Paraná (UTFPR-Curitiba), área de concentração "Linguagem e Tecnologia", na linha de pesquisa "Estéticas Contemporâneas, Modernidade e Tecnologia".
\end{abstract}

\begin{tabular}{l|l|l|l|l} 
Textura & Canoas & v. 20 n. 42 & p. 83-105 & jan/abr. 2018. \\
\hline
\end{tabular}




\section{CONSIDERAÇÕES PREMILINARES}

A literatura infantil vem se modificando consideravelmente desde os primeiros livros para crianças, publicados já no século XVII e, de maneira mais intensa, a partir da primeira metade do século XVIII ${ }^{3}$, após a introdução de novo tratamento à infância, vista a partir de então como faixa etária diferenciada, merecedora de cuidado e atenção específicos.

Tanto nos temas e abordagens - inicialmente ligados intimamente ao caráter pedagógico e moralizante, típico da sociedade burguesa em que floresceu -, como nos recursos e formatos utilizados - com a paulatina valorização das ilustrações e do tratamento gráfico dado ao livro, por exemplo - , muito mudou desde então.

Hoje, vivemos um momento histórico em que convivem as mais diversas manifestações literárias destinadas ao público infantil e juvenil, em variados tipos de suportes e propostas. Entre estas, as disponibilizadas em ou desenvolvidas para o meio digital, onde temos desde livros transpostos para esse ambiente - que são como versões dos livros impressos, nos formatos PDF ou ePub, por exemplo - às mais variadas formas de livros feitos para o digital: versões interativas feitas em ePub, e-books para serem lidos em leitores digitais, como Kindle e Kobo, livros aplicativos que permitem a utilização de várias mídias e diferentes interações, até livros de realidade aumentada, que possibilitam a sobreposição de imagens criadas digitalmente em um cenário

${ }^{3}$ É comum atribuir-se o início da produção de livros infantis ao século XVII, com obras como Fábulas, de La Fontaine (publicadas entre 1668 e 1694) ou Histórias ou narrativas do tempo passado com moralidades (nome original de Contos da Mamãe Gansa), publicada por Perrault em 1697. Leonardo Arroyo, por exemplo, em sua obra Literatura infantil brasileira - considerada um clássico da historiografia da literatura para crianças no Brasil, publicada pela primeira vez em 1968 -, atribui àquele século "o aparecimento do livro infantil" (ARROYO, 2011, p. 14), embora fale sobre raízes ainda bem anteriores e considere o século XVIII como a "Idade de Ouro" dessa literatura (p. 21). Marisa Lajolo e Regina Zilberman, na obra Literatura infantil brasileira: história \& histórias, afirmam que "As primeiras obras publicadas visando ao público infantil apareceram no mercado livreiro na primeira metade do século XVIII" (LAJOLO, ZILBERMAN, 2007, p. 14), declarando que "Antes disso, apenas durante o classicismo francês, no século XVII, foram escritas histórias que vieram a ser englobadas como literatura também apropriada à infância". (grifo nosso) 
real, captado por meio de câmera ou óculos especiais; o que permite, por exemplo, ver os personagens da história na própria sala da nossa casa. ${ }^{4}$

De acordo com Marisa Lajolo e Regina Zilberman, um dos primeiros livros realmente interativos, digitais, multi e hipermídiaticos lançados no Brasil foi o e-book A menina do narizinho arrebitado (FIGURAS 1 e 2), da Editora Globo, versão do livro de Monteiro Lobato, com 56 telas contendo textos verbais e visuais, sons e figuras em movimento. (LAJOLO, ZILBERMAN, 2017, p. 18) ${ }^{5}$.

${ }^{4}$ Essas produções literárias - que se utilizam de recursos popularizados a partir do fenômeno "Pokémon Go", jogo que virou febre mundial e permitia com que os jogadores "caçassem" criaturas virtuais em ambientes reais - começaram a ter visibilidade no mundo editorial e a realidade aumentada já ganhou categoria própria dentro do BolognaRagazzi Digital Award, premiação vinculada à Feira do Livro de Bologna, a partir de 2017.

${ }^{5}$ Matéria sobre o lançamento do livro em iPad, em 2010, afirma que "A menina do narizinho arrebitado é a primeira publicação interativa brasileira para o iPad:'Esta é a primeira obra brasileira no iPad que permite a interatividade. Em uma das passagens, durante à noite, o leitor clica com a ponta dos dedos na tela do tablet, em cima do desenho de um vagalume, e ao arrastar o personagem, ilumina as áreas onde está o texto', explica o diretor da Globo Livros, Mauro Palermo". Matéria disponível em: http://g1.globo.com/tecnologia/noticia/2010/08/livro-de-monteiro-lobato-e-primeirapublicacao-interativa-do-ipad-no-brasil.html. Acesso em: 20 out. 2017. Demonstração do livro em iPad disponível em: https://www.youtube.com/watch?v=eXfhl7OTT44 . Acesso em: 20 out. 2017. 

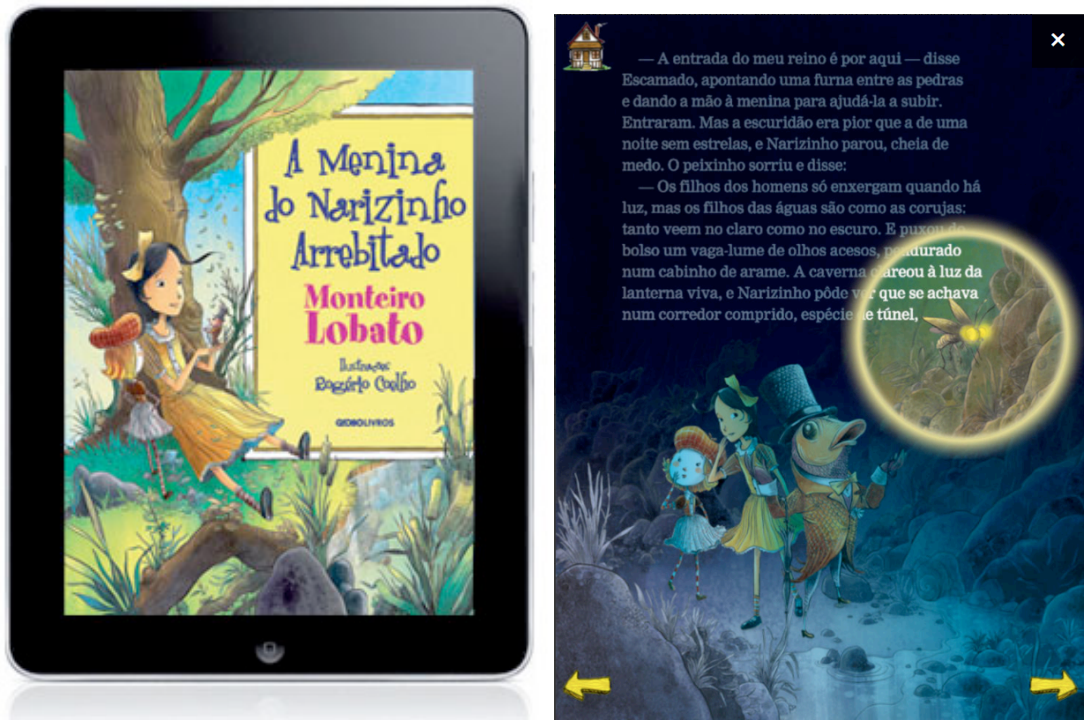

FIGURAS 1 e 2 - A menina do narizinho arrebitado, um dos primeiros livros digitais interativos do Brasil, não mais disponível no site da editora. Fotos de divulgação.

Neste artigo, nosso foco é o livro digital interativo no formato de livroaplicativo, ou app-book, construído com software próprio para ser fruído a partir de telas sensíveis ao toque (touchscreen), contando com recursos multimídia, como animações, narração, efeitos de áudio, vídeos, entre outras possibilidades.

Aline Frederico assim define o livro digital interativo:

[...] é um novo formato de expressão literária voltado ao público infantil que expande as narrativas verbo-visuais características do livro ilustrado impresso ao incorporar sons, movimentos e interatividade. Desde 2010, com o surgimento do iPad, esses livros aparecem principalmente como aplicativos para dispositivos móveis, por exemplo tablets e celulares (por isso são chamados livros-aplicativos ou book/picturebook apps), tendo suplantado o livro interativo em formato de CD-ROM, cujos acessos e popularidade eram limitados. [...] o formato, peso e portabilidade desses dispositivos móveis permite que as narrativas digitais dos livros-aplicativos se aproximem significativamente da experiência de leitura do livro impresso, 
enquanto a tecnologia touch-screen permite uma participação direta do leitor na narrativa, sem o intermédio do mouse. (ALYAQOUT, 2011, apud FREDERICO, 2016, p. 105)

Trata-se de um formato ainda recente na literatura infantil e juvenil, uma vez que é feito para dispositivos tecnológicos desenvolvidos há pouco tempo. $\mathrm{O}$ iPad, um dos principais dispositivos que permitem a leitura desses livros, no sistema operacional móvel da Apple (iOS), começou a ser vendido nos Estados Unidos apenas em abril de 2010, só chegando às lojas brasileiras no final do mesmo ano, enquanto os tablets touchscreen de sistema operacional Android começaram a ser vendidos depois (HARRISON, 2010; BRENTANO, 2010).

Há apenas cinco anos, a crítica voltou sua atenção para os livros digitais. A Feira do Livro de Bolonha, na Itália, o mais importante evento do segmento infantil e juvenil do mundo, sempre atento às inovações no campo, instituiu, em 2012, o BolognaRagazzi Digital Award, prêmio aberto a participantes de todo mundo, que avalia excelência e inovação em conteúdo digital para o público jovem. Na edição de 2017, foram analisadas 152 produções, de 32 países ${ }^{6}$. No Brasil, o Prêmio Jabuti - a mais tradicional premiação do mercado livreiro nacional, promovida pela Câmara Brasileira do Livro desde 1959 introduziu a categoria Infantil Digital, ainda de maneira experimental, em 2015, na $57^{\mathrm{a}}$ edição do prêmio. Em 2015, a categoria teve 40 inscritos, caindo para 16 na edição de $2016^{7}$. Os dados de inscritos na edição de 2017 não haviam sido divulgados até a entrega do presente artigo.

No lançamento daquela edição do Jabuti, quando se anunciavam as duas novas categorias implantadas - Infantil Digital e Adaptação -, Marisa Lajolo, então curadora do Prêmio, afirmou: "[...] estamos contemplando aqui duas das tendências mais contemporâneas da produção cultural não só brasileira mas

${ }^{6}$ Dados disponíveis em: http://www.bolognachildrensbookfair.com/en/the-fair/newevents-and-programmes/bologna-digital-media/bolognaragazzi-digital-award-

2017/2094.html. Acesso em 20 out. 2017. Na edição de 2017, o BolognaRagazzi Digital Award ampliou o olhar para a literature digital, conferindo aos livros de realidade aumentada uma categoria própria.

${ }^{7}$ Disponível em: http://cultura.estadao.com.br/blogs/babel/poesia-bate-recorde-deinscricao-no-jabuti-e-digital-infantil-nao-decola/. Acesso em 20 out. 2017. 
ocidental" ${ }^{, 8}$. Em matéria publicada pela imprensa em $2016^{9}$, Lajolo afirma que há quem ame e quem odeie o livro digital, assunto gerador de muita discussão, mas reafirma a necessidade de refletir sobre o tema: "[...] Os digitais inscritos nesses dois anos são bom ponto de partida para a reflexão sobre esse novo meio de publicação, porque é no livro infantil que acontecem as inovações mais significativas".

George Steiner, ao abordar a função da crítica, afirma que um de seus aspectos é avaliar a literatura contemporânea, tendo o crítico "responsabilidades especiais para com a arte de sua própria época" (STEINER, 1988 [1967], p.58). Considerando o livro digital interativo como fenômeno de linguagem da nossa época e a literatura infantil e juvenil como terreno fértil para "inovações significativas", fica clara a necessidade de pensarmos sobre a literatura digital feita para esses públicos. Para isso, partimos da análise de um dos objetos por nós estudados no projeto de mestrado em Estudos de Linguagens, na área de concentração Linguagem e Tecnologia, da Universidade Tecnológica Federal do Paraná (UTFPR-Curitiba), o livroaplicativo Pequenos grandes contos de verdade, vencedor do primeiro lugar da categoria Infantil Digital do Prêmio Jabuti, em 2016. Para a análise, verificaremos a linguagem verbal e a não-verbal, as cores, o som, a animação e a interação dos três contos.

\section{PEQUENOS GRANDES CONTOS DE VERDADE}

O livro-aplicativo Pequenos grandes contos de verdade (FIGURA 3), de Oamul $\mathrm{Lu}$ e Isabel Malzoni, foi disponibilizado pela Caixote Editora Comércio de Livros e Desenvolvimento de Softwares Ltda., em 7 de julho de 2015, tendo tido pelo menos duas atualizações, para correções, feitas em 09 de novembro de 2016 e em 20 de outubro de 2017 (versão 1.3.1). Foi feito apenas para leitura em dispositivos do sistema iOS, podendo ser baixado em iPad ou

${ }^{8}$ CÂMARA BRASILEIRA DO LIVRO, 2015, áudio em $12 \mathrm{~min} 20$.

${ }^{9}$ Disponível em: http://www.publishnews.com.br/materias/2016/08/05/jabuti-menosconcorrido-em-2016. Acesso em 20 out. 2017. 
iPhone. Vendido pela App Store por US\$ 1,99, o livro também tem uma versão "lite", que pode ser baixada gratuitamente, contendo apenas uma das três histórias disponíveis na versão completa do aplicativo.

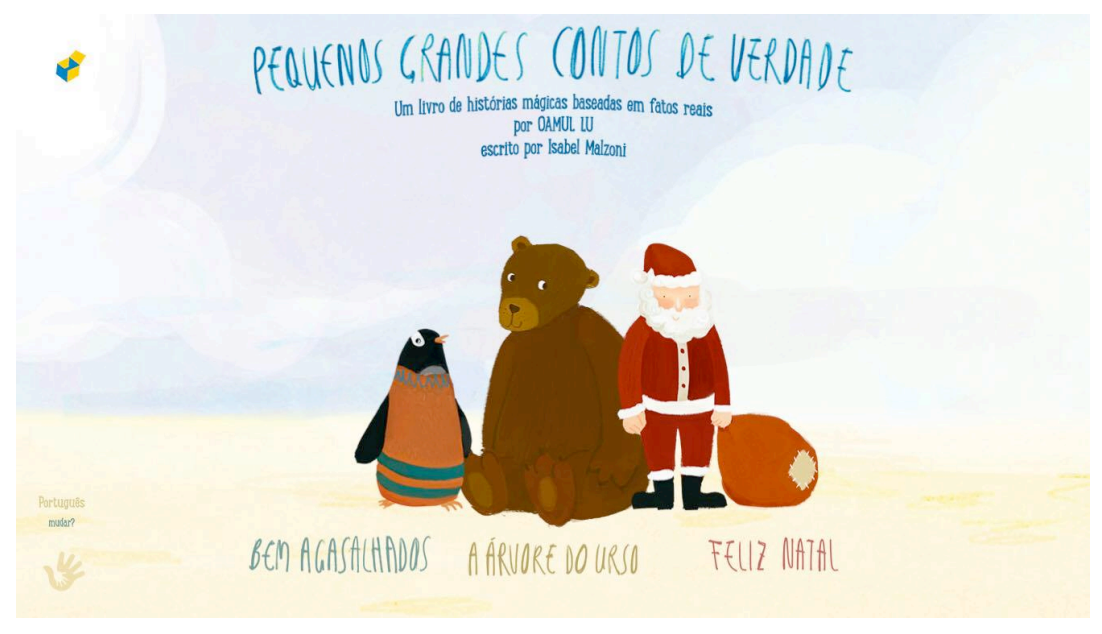

FIGURA 3 -Menu principal do app-book

O conteúdo, desenvolvido para crianças de até cinco anos, é baseado em I found a star, livro do ilustrador chinês Oamul Lu, impresso em mandarim. O livro original tem dez histórias de um parágrafo que acompanham, cada qual, quatro ilustrações de Lu. De acordo com relato de Isabel Malzoni ${ }^{10}$, editora e sócia da Editora Caixote, ela e Per Gustav Hornell, diretor de arte que criou as interatividades do aplicativo, escolheram três das histórias do autor chinês para utilizar no aplicativo - o primeiro lançamento da editora - porque consideraram-nas com maior potencial para exploração no formato digital e porque eram baseadas em fatos que tinham ocorrido na vida real. Malzoni escreveu os contos com base no conteúdo do livro físico, e as animações foram feitas pelo próprio $\mathrm{Lu}$.

\footnotetext{
${ }^{10}$ Matéria disponibilizada no site da Editora Caixote: http://www.editoracaixote.com.br/blog/pequenos-grandes-contos-de-verdade-makingof/. Acesso em: 18 out. 2017.
} 
[...] Guga e eu escolhemos três daquelas histórias para comporem o primeiro aplicativo. Os critérios: aquelas que fossem baseadas em fatos reais (por isso a 'verdade' no título), e que consideramos ter mais potencial de se beneficiar das possibilidades do digital. Mas quando reparamos bem nossos personagens principais - um urso, um pinguim e o Papai Noel -, percebemos que aquelas histórias tinham em comum algo muito mais especial do que nossos critérios iniciais: a solidariedade e o empoderamento. (MALZONI, 2016)

O livro-aplicativo traz três contos: "A árvore do urso", "Feliz Natal" e "Bem Agasalhados". Todas as histórias têm versões em português e inglês e utilizam música instrumental de fundo, efeitos sonoros, animação e interatividade. As cores utilizadas são predominantemente em tons "queimados" e suaves. Há possibilidade de escolha entre a leitura tradicional, do texto escrito na tela, no link: "Eu leio sozinho", ou de narração oral, no link: "Leia para mim". O aplicativo também traz a opção de o próprio leitor, seja criança ou adulto, gravar as histórias em áudio, para ouvi-las posteriormente com sua própria voz ou a voz de alguém de sua convivência. Através do link "Leitura especial", é possível fazer várias gravações, que ficam disponíveis para serem ouvidas quando se desejar ${ }^{11}$.

Nas animações, os personagens podem se comunicar por meio de sons, quase sempre não identificáveis, ou por meio de balões de fala em que não aparecem palavras, mas imagens (FIGURA 4). O leitor é orientado nas interações por meio de textos e áudios explicativos (mesmo na versão "Eu leio sozinho", que não possui narração) e também através de um círculo azul que pulsa ou que se movimenta em determinado sentido para mostrar o local onde a criança deve tocar ou o movimento que deve fazer com os dedos para acontecer a interação (FIGURA 5).

\footnotetext{
${ }^{11}$ No próprio app-book, a editora justifica por que gravar a própria narração, nas seguintes palavras: "Acreditamos que as boas histórias têm o poder de aproximar pessoas, alimentar a criatividade e engrandecer os corações. E por isso que incentivamos todas as pessoas a não abrirem mão de contar histórias para seus pequenos. Com nossos aplicativos, esses momentos podem ser feitos mesmo à distância. Usando a opção "Leitura Especial", presente no menu das histórias, você pode gravar a narração e guardar para que o seu pequeno leitor escute sempre que quiser. Deixe a história ainda mais especial."
} 


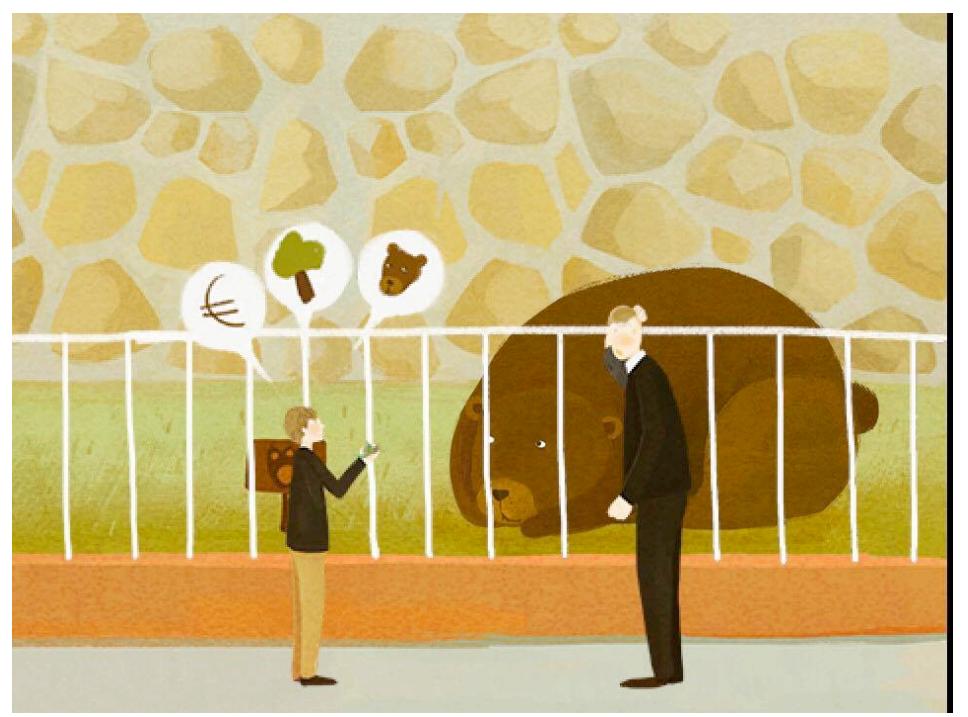

FIGURA 4 - Personagens se comunicam com sons e balões com imagens

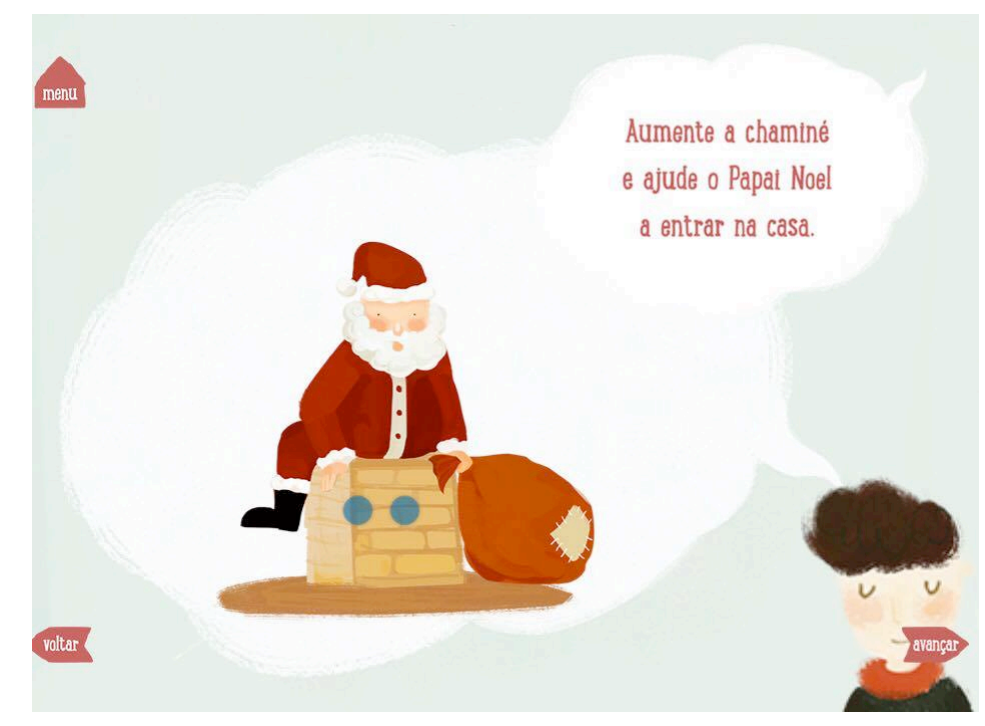

FIGURA 5 - Círculos azuis em movimento mostram a ação que deve ser executada pelo leitor. As instruções são dadas também por escrito, em balões, e a informação ainda é narrada.

Textura, v. 20 n. 42, jan/abr. 2018. 
Na tela de menu, aparecem os três personagens que caracterizam cada conto. Cada qual a sua vez faz um movimento, como levantar a mão ou pular e apontar para si mesmo, sugerindo que o leitor nele clique para ler a sua história. Essa primeira tela também dá acesso à que permite mudança de língua (português ou inglês) e traz um ícone (uma mão espalmada) que leva a uma tela que apresenta a editora. Esta, por sua vez, dá acesso a outra, que traz argumentos sobre a proposta de se gravar sua própria narração e, então, à tela "Por trás do livro-aplicativo", que relaciona as pessoas e empresas que participaram do projeto (créditos), assim como os contatos da editora.

$\mathrm{Na}$ primeira tela de cada história, aparecem as opções: "Leia para mim", "Eu leio sozinho" e "Leitura especial", já mencionadas. Nesse livro digital, os textos escritos aparecem intercalados com sequências de animação. Em cada tela, há as opções "Avançar" e "Voltar", escritas em ícones de flechas que apontam para frente ou para trás, e também um ícone de "Menu", que permite retornar ao menu inicial. Nas telas, o aplicativo só mostra as opções de avanço e retorno após um tempo específico (no caso das telas de leitura de texto da história do urso) ou quando toda a sequência de movimento foi executada (no caso das animações, que têm uma duração maior), não permitindo que o leitor adiante o processo.

"A Árvore do Urso" conta a história de um urso e um menino. A criança conhece o animal no zoológico e considera-o muito triste. Compadecido com a situação, o menino arquiteta um plano para deixar o urso feliz. A narrativa transcorre com as ações do garoto para ajudar o animal, e o leitor interage com a história ajudando o menino a executar essas ações. Ele colhe maçãs e, com a ajuda da avó, produz muitas garrafas de suco para vender a 50 centavos no mercado local. Tendo conseguido reunir o dinheiro necessário, ele volta ao zoológico e pede ao dono do local que use o valor por ele arrecadado para dar um presente ao urso, uma árvore para ser plantada no recinto do animal. E assim é feito, o que deixa o urso muito feliz.

Nessa história, o leitor ajuda o menino a colher as maçãs, clicando nas frutas e arrastando-as para uma cesta. Também participa da produção do suco. No entanto, sua "ajuda", clicando nos vidros de suco, faz com que um deles se quebre, demonstrando os acidentes que podem ocorrer durante o processo. Em outro momento, o leitor clica no menino para que ele continue a vender os sucos de maçã para os transeuntes, na feira. A interação reforça a ideia de solidariedade, tema principal das histórias, fazendo com que as crianças 
leitoras se sintam úteis, participando da trama e ajudando os personagens a realizar suas tarefas.

Com fundo de música instrumental, as telas de texto aparecem intercaladas às que trazem animações contínuas; por exemplo, aquela em que o menino anda pelo zoológico, passando em frente às jaulas de diversos animais, até chegar ao recinto do urso; ou outra em que ele anda entre árvores até chegar às macieiras, para colher as frutas. Os textos escritos variam de duas a três linhas, sendo que cada tela de texto tem uma cor de fundo diferente: cáqui, duas tonalidades de verde, vermelho, cinza, alaranjado; todas cores predominantes também nas cenas animadas do livro.

Os personagens fazem alguns sons, não completamente identificáveis. Quando identificados, percebemos que são palavras da língua inglesa, como "bear" [urso, em português], que pudemos discernir em uma das partes. O menino se comunica com o gerente do zoológico por meio desses sons e por balões de fala onde aparecem imagens, tais como símbolo de dinheiro (euro), árvore, urso.

$\mathrm{Na}$ comunicação não verbal, também podemos perceber gestos como aceno com a mão, coçar a cabeça para pensar, ter uma ideia - demonstrada através de movimento com o dedo em riste e do aparecimento de uma lâmpada ao lado da cabeça. Na parte em que o leitor deve ajudar o menino a colher as maçãs, o personagem comemora quando o usuário consegue levar a fruta até a cesta e abaixa a cabeça quando aquele não o consegue. Concomitantemente, há um efeito sonoro que indica frustração. $\mathrm{O}$ livro tem seguimento quando $\mathrm{o}$ usuário consegue colher cinco frutas, após o menino passar a mão na testa, como se o trabalho de colher as maçãs o tivesse cansado.

Também há outros efeitos sonoros, como o barulho do vidro de suco que quebra e o som da multidão na feira onde o menino vende a sua produção a 50 "cents". Chama atenção a placa com o escrito "50 ф", assim como a tela em que temos o símbolo do euro, revelando que a moeda utilizada não é a brasileira.

A sinalização do que o leitor deve fazer para interagir ocorre de três formas diferentes: por meio de um círculo azul, que faz o movimento esperado do usuário; por meio de texto escrito em um balão de fundo branco; e ainda com a narração desse mesmo texto (o conteúdo da orientação é narrado em áudio, mesmo na versão para ler sozinho). Ora as três formas estão juntas, ora aparece apenas o círculo azul. 
O conto "Bem Agasalhados", por sua vez, fala da situação de pinguins afetados pelo vazamento de petróleo de um navio que viajava pela costa da Nova Zelândia. O produto gruda na pele das aves, prejudicando sua proteção contra o frio e deixando-as doentes. Veterinários limpam os animais, mas o cuidado inicial não é suficiente: eles precisam de tempo para se recuperar totalmente e ainda sentem frio. Então, uma veterinária tem uma ideia: fazer casacos de lã para vesti-los. A ideia se espalha pelo país e várias pessoas tricotam casacos para salvar os pinguins, que desfilam, então, alegremente vestidos.

Nessa história, o leitor pode interagir para chamar o veterinário e para limpar um pinguim, esfregando o dedo na tela, conforme as sinalizações indicadas pelo círculo azul e pelos textos e áudios explicativos, reforçando novamente a temática da solidariedade. As telas estáticas têm textos de duas a quatro linhas, com fundos em tons de azul, cáqui e vermelho. $\mathrm{O}$ azul, o cáqui e o preto são as tonalidades mais marcantes nesse conto. Novamente são utilizados efeitos sonoros, como o toque do telefone, quando o leitor clica no círculo azul para chamar o veterinário; o som da esfregação, quando o leitor ajuda a limpar o pinguim; o das pegadas do pinguim, sujo e triste, logo após o derramamento do petróleo; ou o das agulhas tricotando casacos, em várias partes do país. Também é possível identificar um som emitido pelo veterinário: a palavra "hello", que ele diz quando aparece pela primeira vez, chamado pelo toque do leitor no círculo azul.

A cena mais poética é da primeira tela, em que, ao som (sempre constante) da música instrumental, o navio aparece navegando entre céu e mar e, então, o petróleo começa a vazar, inundando paulatinamente a tela de preto.

No conto "Feliz Natal", por sua vez, uma família compra uma casa nova, grande e bonita, mas um detalhe preocupa o filho: a chaminé é pequena demais para o Papai Noel entrar com os presentes de Natal. Ele, então, com a ajuda da mãe, escreve uma carta para o construtor, que resolve o problema, refazendo a chaminé e possibilitando que o menino receba a visita de Noel e tenha um Natal feliz. ${ }^{12}$

${ }^{12} \mathrm{O}$ conto, como os demais, é baseado em fatos reais. Nesse caso, a história do garoto que queria ampliar a chaminé foi contada por um jornal americano e, inclusive, registrada em vídeo. A história é contada no próprio site da editora: http://www.editoracaixote.com.br/blog/historia-real-pequenos-contos-de-verdade/ Acesso em: 30 out. 2017. 
Nessa história, a interação é feita em três momentos. O primeiro, quando o leitor clica sobre a família, e o Papai-Noel aparece no canto da tela, acenando. $O$ segundo, quando deve-se fazer um movimento de abertura, separando dois dedos e fazendo com que a chaminé se amplie e o Papai-Noel caia dentro da casa. Num terceiro momento, o leitor deve ajudar o menino a depositar a carta na caixa de correio e, então, a entregá-la ao destinatário, conduzindo-a da caixa para a mesa do construtor (FIGURA 6), fazendo também com que a criança leitora possa participar da tarefa realizada.

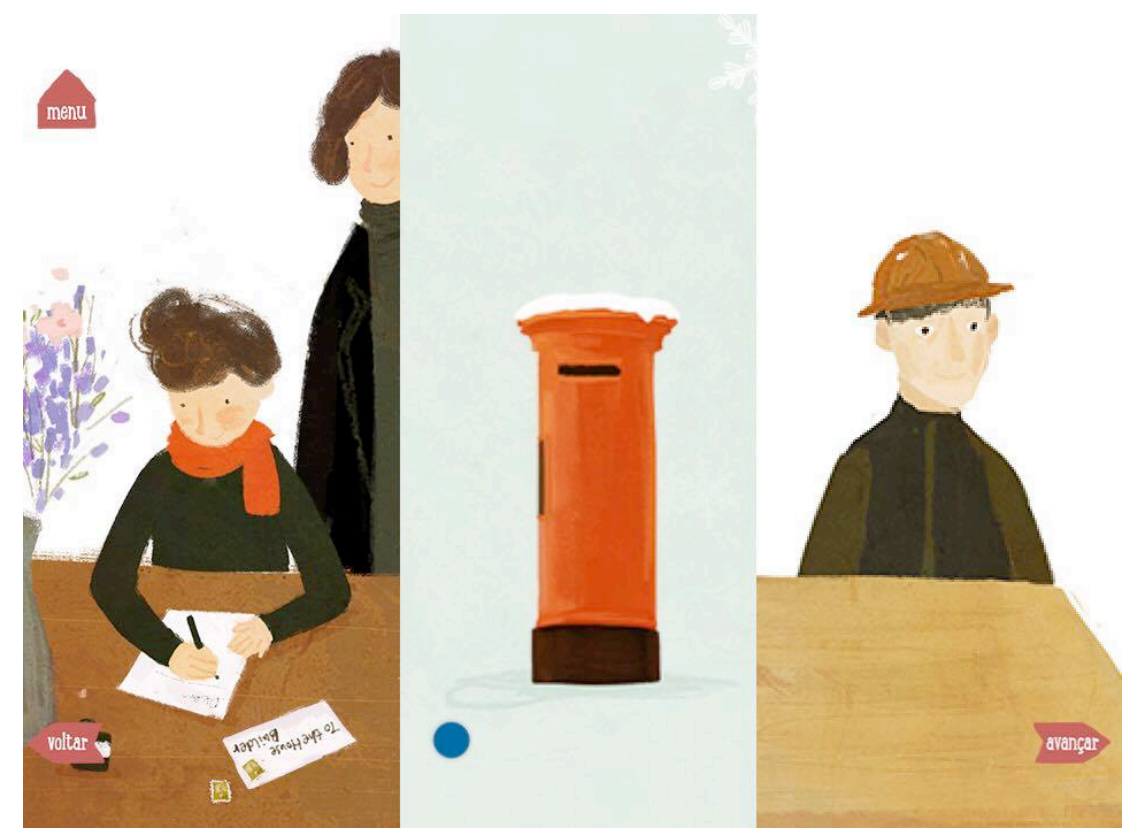

FIGURA 6 - Numa mesma tela, o leitor ajuda o menino postar a carta e fazê-la chegar ao construtor, movimentando o dedo no sentido que é mostrado pelo círculo azul.

Verificamos que as três histórias, todas direcionadas a leitores de até cinco anos - como informado na página de compra do aplicativo -, não possuem muitos momentos de interação, o que é justificado pela editora, nas seguintes palavras:

A nossa intenção, desde o início, era usar as possibilidades do digital para contar as histórias de um jeito ainda mais encantador 
e engajar as crianças. Então fomos criando interatividades ao longo do texto para que os leitores fizessem parte do desenrolar da narrativa e pudessem ainda ajudar os personagens em suas jornadas. Mas atentamos muito para não criar interatividades desnecessárias ou excessivas porque a história era o mais importante, e não os botões. (MALZONI, 2016)

Notamos, assim, que o valor da solidariedade, já focalizado pela própria trama, pela narrativa textual, é reforçada pelo recurso da interatividade. Ou seja, nas interações, o leitor ajuda o personagem principal a auxiliar outro personagem. $\mathrm{O}$ fato de contar com múltiplas linguagens enriquece a poética do texto e a interatividade ajuda a reforçar a intencionalidade da narrativa, porque leva o leitor a também ser solidário com os personagens.

É interessante observar, ainda, o caráter internacional do projeto, que envolve brasileiros e um chinês, nos símbolos e termos utilizados, que podem não ser tipicamente nacionais, mas que são reconhecidos globalmente. $\mathrm{Na}$ história "A árvore do urso", por exemplo, quando o menino se refere a dinheiro, o ícone que aparece é o símbolo da moeda da União Europeia, o euro $(€)$. Na história "Feliz Natal", a caixa de correio não tem padrões brasileiros; lembra as tipicamente inglesas, vermelhas e arredondadas. A própria carta escrita pelo garoto traz no envelope o destinatário em inglês: "To the House Builder" [Para o construtor]. E, no final da história, mesmo na versão em português, o menino agradece dizendo "thank you" [obrigado] - um dos únicos termos que são inteligíveis na fala de um personagem do livro. Tais palavras também aparecem por escrito no balão de fala que surge na mesma tela.

Essas situações, no entanto, não comprometem o entendimento da obra por uma criança de cultura diferente - pelo menos a pertencente a uma classe que tenha acesso aos bens culturais e aos dispositivos tecnológicos necessários para a leitura do app-book ${ }^{13}$, demonstrando-se, assim, como esse tipo de iniciativa multimidiática pode ser multicultural, explorando diferentes recursos para atingir públicos diversos, favorecida pela forma de distribuição do produto, que é exclusivamente online.

${ }^{13}$ Se pensarmos no casoespecificamente brasileiro das classes menos privilegiadas, possivelmente a moeda utilizada, a caixa de correio, o uso da língua inglesa não farão parte de seu repertório cultural cotidiano. 


\title{
O CONSUMO DE APARELHOS ELETRÔNICOS MÓVEIS
}

De acordo com previsão da $28^{\mathrm{a}}$ Pesquisa Anual de Administração e Uso de Tecnologia da Informação nas Empresas, da Fundação Getúlio Vargas de São Paulo, realizada pelo Centro de Tecnologia de Informação Aplicada da Escola de Administração de Empresas de São Paulo (FGV/EAESP), divulgada em abril de 2017, o Brasil terá, até o final deste mesmo ano, um smartphone em uso por habitante. A base instalada de telefones móveis conectáveis à internet seria, até outubro, de 208 milhões de aparelhos ${ }^{14}$, o equivalente a um celular "inteligente" para cada habitante. Segundo a pesquisa, já teríamos 280 milhões de dispositivos móveis com acesso à internet, incluindo notebooks, tablets e smartphones, representando 1,4 dispositivo portátil por habitante. $\mathrm{O}$ número de computadores em funcionamento - somados notebooks, desktops e tablets - é de 162,8 milhões, segundo o levantamento. Até o final do ano de 2017, seriam 166 milhões - incluindo cerca de 33 milhões de tablets.

Fernando Meirelles, coordenador da pesquisa, realizada desde 1988, afirma em matéria divulgada pela imprensa que "estamos assistindo a um novo comportamento no uso de dispositivos" ${ }^{\prime \prime}$ :

\begin{abstract}
Isso pode ser analisado a partir da queda na venda de computadores nos últimos anos. Em 2016, o mercado encolheu $15 \%$ em número de unidades vendidas (12 milhões) - o terceiro ano consecutivo que isso acontece. Para este ano, se estima o mesmo patamar.
\end{abstract}

De acordo com o professor, essa falta de interesse na compra de computadores mostra que o consumo foi direcionado para outro aparelho: o smartphone. Além disso, o público também mudou. 'Quando mais jovem, maior é o uso e a compra de celulares inteligentes', disse. (REVISTA EXAME (online), 19/04/2017)

\footnotetext{
${ }^{14}$ Dados disponíveis em: http://link.estadao.com.br/noticias/gadget,ate-o-fim-de-2017brasil-tera-um-smartphone-por-habitante-diz-pesquisa-da-fgv,70001744407. Acesso em 20 out. 2017.

${ }^{15}$ Disponível em: https://exame.abril.com.br/tecnologia/brasil-tera-um-smartphone-porhabitante-ate-outubro-diz-fgv/. Acesso em 20 out. 2017.
} 
Percebe-se que o uso dos aparelhos eletrônicos móveis, sobretudo dos smartphones, é realidade para um número significativo de pessoas, principalmente, entre os mais jovens. Essa realidade já é facilmente percebida pelos atores do meio educacional, por exemplo, na instituição particular de Curitiba, Paraná, a Escola Trilha, que oferece Educação Infantil e Ensino Fundamental I, de $1 .^{\circ}$ ao $5 .^{\circ}$ ano, há 13 anos realiza um simpósio anual sobre criança, mídia e consumo ${ }^{16}$. O simpósio objetiva promover reflexões teóricas, pesquisas e produções em relação ao tema com os alunos. Em 2017, inseriu a problemática do uso de tablets e celulares entre os temas do evento. Até o ano anterior, o assunto mais ligado à tecnologia era o excesso do uso da televisão. Agora, pela primeira vez, fala-se amplamente sobre "telas". No evento, realizado em 21 de outubro de 2017, os alunos do quarto ano, após criarem conjuntamente o roteiro, encenaram uma peça em que "as telas" eram rés em um julgamento pelos "crimes" de hipnotização das pessoas diante dos aparelhos eletrônicos, consumo em excesso, desconcentração das crianças, diminuição do tempo de brincadeiras não eletrônicas, invasão da privacidade e alienação. Após os argumentos encenados, o público participava como integrante do júri popular, votando pela absolvição ou condenação das telas. Nas duas apresentações a que assistimos, de uma das turmas de quarta série, os dispositivos eletrônicos foram "absolvidos".

Esse relato é apenas uma pequena ilustração do fato de que o uso dos aparelhos móveis é cada dia mais aceito pelos pais e naturalizado pelas crianças, cabendo às famílias e aos que pensam a educação refletir sobre como aproveitar esses novos recursos em prol de um uso que possa agregar cultura e conhecimento.

\begin{abstract}
A literatura digital [...] cria as práticas que nos ajudam a saber mais sobre as implicações de nossa situação contemporânea. [...] a literatura eletrônica contemporânea é tanto reflexão quanto representação de um novo tipo de subjetividade caracterizada pela cognição distribuída, uma ação em rede que inclui atores humanos e não humanos e limites flexíveis dispersos por espaços reais e virtuais. (HAYLES, 2009, p. 48)
\end{abstract}

Numa geração que já nasce no mundo virtual midiático, em meio a jogos de computador, das artes digitais, dos aparelhos de celular, tablets, smartphones e outras formas associadas à mídia em rede programável, a

\footnotetext{
${ }^{16}$ Para saber mais sobre a proposta do evento: https://www.escolatrilhas.com.br/aescola/projetos/simposio-crianca-midia-e-consumo/. Acesso em 21 out. 2017.
} 
literatura digital, antes de ser temida, poderia agregar variedade e possibilitar novas formas de fruição literária. Nesse contexto é que podem entrar os livros digitais desenvolvidos para essas plataformas.

\section{A QUESTÃO DA MATERIALIDADE E DO ACESSO}

A fim de que pensemos na possibilidade futura de utilização dos livrosaplicativos como recurso educativo em escala, é necessário que prestemos atenção às questões relativas à materialidade e ao acesso a esses produtos.

Para que uma criança tenha acesso aos livros-aplicativos como os que tratamos neste estudo, é necessário, primeiramente, que elas, suas famílias ou escolas tenham os dispositivos necessários para que esses produtos, em grande parte dos casos, pagos, possam ser baixados e lidos. Além disso, determinados livros só funcionam em determinado sistema operacional. Isso significa que, mesmo que a criança tenha acesso a um tablet ou smartphone, ela não necessariamente conseguirá baixar determinado livro.

Para exemplificarmos: se quiséssemos ler hoje os seis app-livros premiados nas duas primeiras edições do Prêmio Jabuti (2015 e 2016), teríamos necessariamente que ter acesso a dispositivos dos dois sistemas operacionais, iOS e Android. Se tivéssemos acesso apenas a um dispositivo Android, não poderíamos ler Pequenos Grandes Contos de Verdade, por exemplo, pois só funciona em aparelhos iOS. Se tivéssemos apenas um dispositivo iOS, não poderíamos acessar Chove Chuva, livro-aplicativo classificado em terceiro lugar em 2016, porque este é feito apenas para Android. E ainda que tivéssemos um iPhone (que funciona com o sistema iOS), não poderíamos ler o livro Mãos Mágicas, por exemplo, que embora funcione no mesmo sistema, só é passível de ser lido em iPad. Ou seja, temos mais restrições em relação à materialidade no livro digital interativo do que ocorria com o livro impresso, que poderia, por exemplo, ser encontrado em uma biblioteca.

Outra questão importante ligada à materialidade do app-book é que embora os dispositivos móveis possam ser compartilhados em alguns casos, como tablets em escolas -eles são equipamentos focados no uso individual. Dificilmente alguém compartilha um celular, por exemplo. Assim, a nosso ver, os livros-aplicativos desenvolvidos dentro dessa materialidade teriam menor 
possibilidade de alcançar mais leitores por unidade baixada, como ocorre com os livros tradicionais.

Dessa forma, esse tipo de livro, como recurso educativo no Brasil, ainda mostra-se distante do público potencial, a nosso ver, porque ainda não é largamente divulgado; porque as escolas, sobretudo as públicas, não têm amplo acesso a esses recursos tecnológicos; e porque ainda não existem muitas bibliotecas com livros digitais acessíveis ao público em geral ou a escolares ${ }^{17}$.

Regina Zilberman, respondendo à questão por nós formulada, em público $^{18}$, em evento realizado no dia 23 de outubro de $2017^{19}$, em Curitiba, falou o seguinte sobre o cenário da literatura digital no país e os entraves da materialidade exigida para a sua fruição:

Tem um pouco de futurologia nessa sua pergunta mas, de qualquer forma, eu não estou vendo crescer muito a produção digital brasileira. Através de e-readers, e-books... não sei se já é um nicho rentável. Enquanto não se mostrar rentável, ele não vai

\begin{abstract}
${ }^{17}$ Das poucas iniciativas que conhecemos de bibliotecas digitais voltadas a escolas, no Brasil, está a plataforma Árvore de Livros (www.arvoredelivros.com.br/), que disponibiliza mais de 10 mil títulos, a maioria, no entanto, ainda no modelo PDF, a partir de parcerias e contratos com editoras e prefeituras. O sistema possibilita, inclusive, que o professor acompanhe a frequência e a qualidade da leitura de cada um dos alunos que acessa a plataforma. Parte dessas informações constam em matéria jornalística sobre a implantação do sistema em um município paulista, que pode ser acessada no link: http://g1.globo.com/sp/bauru-marilia/tem-noticias1edicao/videos/v/iniciativa-em-lencois-paulista-disponibiliza-livros-digitais-para-alunosda-rede-publica/6229216/. Acesso em: 30 out. 2017. Outros dados foram obtidos durante aula expositiva, com acesso à plataforma, ministrada pelo professor Galeno Amorin, em 17 de março de 2017, na PUC-PR, como parte da disciplinaBibliotecas Digitais, da Pós-Graduação em Produção e Gestão Editorial Multiplataforma.

${ }^{18}$ Questões por nós formuladas: A senhora acha que a atenção da crítica para os livros digitais interativos, com a criação da categoria Infantil Digital, pelo Prêmio Jabuti, em 2015, fez com que aumentasse o interesse dos autores e editores na produção do digital infantil? E quanto aos leitores, as crianças? Eles realmente se interessam pelo livro digital? Tendo em vista que a leitura dos livros digitais depende da materialidade do objeto, ou seja, do dispositivo em que funciona, quando a senhora acha que esse tipo de produção vai chegar às escolas, sobretudo públicas, como recurso de leitura?

${ }^{19}$ Bate-papo realizado na Festa Literária da Biblioteca Pública do Paraná, em 23 de outubro de 2017, gravado em áudio pelas autoras. Informações sobre o evento: http://www.bpp.pr.gov.br/modules/noticias/article.php?storyid=1009. Acesso em: 30 out. 2017.
\end{abstract}


progredir muito. E há um outro semi-nicho - digamos assim que poderia até ter mais oportunidades... mas no Brasil... não consigo identificar ainda em termos de visibilidade, que é a produção digital online. Essa, por enquanto, eu acho que se encontra em outros locais... Na Europa, alguma coisa... mas eu acho, acho, que ainda é muito incipiente o que tem a ver com a segunda questão que tu traz, que depende de um suporte que ainda é relativamente caro. Eu acho que o suporte ainda... se bem que um kindle, kobo, etc, não são caros... para os aplicativos de livro digital, que requerem um pouco mais de memória, de velocidade, etc, que não sei se nós temos poder aquisitivo para isso. Então isso também retarda. Há também um terceiro aspecto que é a reação da própria sociedade. Há ainda uma certa reserva da sociedade: "ah, não sei quê... será que é... será que não é...", isso também compromete, no sentido de uma expansão ampla, que é uma reação historicamente identificável. Quando aparece o livro impresso, século XVI, século XVII: "ah, isso aí é arma do diabo". Tende a ser visto como algo diabólico. Também no século XVIII, XIX, quando o público feminino cresce: "ah, essas mulheres deviam estar cuidando é de filho, da cozinha, em vez de estar lendo". Então, a sociedade se protege contra as inovações com uma certa reação. Eu acho que isso também é um elemento; que o produto digital de literatura é muito novo ainda e as pessoas sentem um certo incômodo. Não entrou rachando como o Facebook, o Orkut, essas outras redes... não tem essa mesma facilidade. Aí entra também a questão da disponibilidade para chegar na escola: quando ele chega na escola, se chega... eu acho que as escolas particulares, privadas, que atendem a classe $\mathrm{A}$, elas usam normalmente notebooks, tablets, smartphones, em sala de aula, nem pensam mais em livros; isso para a escola pública é impensável. A escola pública teria que fornecer esse material. E aí começa: "ah, porque vão quebrar, porque vão destruir”. É sempre a reação convencional a esse tipo de avanço. Ou seja, a literatura, o ensino por meio de suportes digitais, só acentuam uma desigualdade na formação da infância brasileira. Quer dizer... que a escola particular, privada, tem uma educação esmeradíssima, e a plebe fica entregue a prédios caindo aos pedaços, falta de luz... tem multimídia mas precisa ser consertada, o ar condicionado estragou, e assim por diante. Quanto mais a tecnologia avança, mais ela tem, no Brasil, aumentado as distâncias sociais, infelizmente... essas desigualdades. Pelo menos é uma percepção que eu tenho baseada numa em uma experiência empírica, não fiz pesquisa. (ZILBERMAN, 2017. Resposta a questão formulada em evento público) 
Infelizmente, observa-se, hoje, também nessa seara, uma questão de desigualdade social, em que as classes menos privilegiadas vivenciam processo de exclusão também no acesso a esses bens culturais, não podendo usufruir plenamente de seus direitos como cidadão, em especial, do "direito à literatura" proclamado por Candido ${ }^{20}$.

\section{CONSIDERAÇÕES FINAIS}

Observando algumas das recentes produções de livros-aplicativos feitos no mercado nacional, como a que descrevemos neste artigo, assim como a qualidade que vêm alcançando; verificando o potencial de interação e de engajamento do leitor que tais produções parecem proporcionar (aí a necessidade de comprovação com novos estudos sobre a recepção dessas produções por parte das crianças); e constatando as tendências no uso dos aparelhos móveis pelos mais jovens, parece-nos claro que o livro digital interativo possa ser um meio a mais de captar leitores e desenvolver o gosto pela leitura em nossas crianças.

Para que isso realmente ocorra no âmbito das escolas, sobretudo públicas, no entanto, é necessária, junto a uma maior oferta de bibliotecas digitais, uma ampliação em sua estrutura tecnológica, que venha simultaneamente com a capacitação dos docentes em educação digital, possibilitando o conhecimento e a competência necessários para que possam trabalhar como mediadores de leitura multiletrada, num mundo de crianças nativas digitais.

Dominique Wolton afirma que:

O progresso técnico não pára de reduzir os intermediários para permitir uma comunicação direta [...]. E, paulatinamente, se redescobre a importância dos intermediários, de facilitadores para nos ajudar a circular nos imensos continentes do saber, de dados, de conhecimento. A ideia de uma informação e de um conhecimento direto é um mito perigoso. Aliás, o ideal da democracia não visa jamais a suprimir os intermediários, mas, ao contrário, melhor, lhes assegurar o seu papel. (WOLTON, 2012, p. 194)

\footnotetext{
${ }^{20}$ Antonio Candido trata a literatura como um direito humano em seu célebre texto: "O direito à literatura" (In: Vários Escritos. Rio de Janeiro: Ouro sobre Azul, 2011).
} 
Assim, conhecer as novas possibilidades de leitura e fomentar o acesso aos meios que permitam um trabalho consistente com as crianças é mister para quem pensa em uma educação que não se perca no tempo.

\section{REFERÊNCIAS}

"A menina do narizinho arrebitado" para iPad. Demonstração disponibilizada pela Globo Livros no Youtube. 20 Ago. 2010. Disponível em: https://www.youtube.com/watch?v=eXfhl7OTT44. Acesso em 20 out. 2017.

ARROYO, Leonardo. Literatura infantil brasileira. 3. ed. rev. e ampliada. São Paulo: Editora Unesp, 2011. 408 p.

BolognaRagazzi Digital Award 2017. Bologna Childrens Bookfair. Disponível em: http://www.bolognachildrensbookfair.com/en/the-fair/newevents-and-programmes/bologna-digital-media/bolognaragazzi-digital-award2017/2094.html. Acesso em 20 out. 2017.

BRENTANO, Laura. Primeiro consumidor na fila para iPad comprou aparelho para presente: Aparelho chega às lojas a partir de $\mathrm{R} \$ 1.649$. Tablet foi lançado no Brasil à meia-noite. G1. Rio de Janeiro, 03 dez. 2010. Tecnologia e Games, p. $0-0$. Disponível em: $<$ http://g1.globo.com/tecnologia/noticia/2010/12/primeiro-consumidor-na-filapara-ipad-comprou-aparelh>. Acesso em: 13 jun. 2017.

CÂMARA BRASILEIRA DO LIVRO (São Paulo). Evento na íntegra. 2015. Evento de lançamento da $57^{\mathrm{a}}$ edição do Prêmio Jabuti. Disponível em: <https://soundcloud.com/camarabrasileiradolivro/evento-naintegra-1>. Acesso em: 08 jun. 2017.

CANDIDO, Antonio. A literatura e a formação do homem. In: Ciência e

Cultura. São Paulo, v. 24, n.9, p. 803-809, set. 1972.

. O direito à literatura. In: . Vários escritos. 3.ed. rev. ampl. São

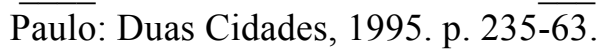


CAPELAS, Bruno. Até o fim de 2017, Brasil terá um smartphone por habitante, diz FGV. O Estado de S. Paulo. São Paulo, 19 abr. 2017. Disponível em: http://link.estadao.com.br/noticias/gadget,ate-o-fim-de-2017brasil-tera-um-smartphone-por-habitante-diz-pesquisa-da-fgv,70001744407. Acesso em 20 out. 2017.

COELHO, Nelly Novaes. Literatura infantil: teoria, análise, didática. 1. ed. São Paulo: Moderna, 2000.

DEMARTINI, Marina. Brasil terá um smartphone por habitante até outubro, diz FGV. Revista Exame. 19 abr. 2017. Disponível em:https://exame.abril.com.br/tecnologia/brasil-tera-um-smartphone-porhabitante-ate-outubro-diz-fgv/. Acesso em 20 out. 2017.

FREDERICO, Aline. O futuro do leitor ou o leitor do futuro: o livro infantil interativo e os letramentos múltiplos. Cadernos de Letras da UFF. Dossiê: A crise da leitura e a formação do leitor, $\mathrm{n}^{\circ}$ 52. 2016. p. 101-120. Disponível em: http://www.cadernosdeletras.uff.br/index.php/cadernosdeletras/article/view/19 5. Acesso em: 18 out. 2017.

HARRISON, Natalie; KERRIS, Natalie. IPad Available in US on April 3. 2010. Release disponibilizado na página da empresa Apple. Disponível em: $<$ https://www.apple.com/newsroom/2010/03/05iPad-Available-in-US-onApril-3/>. Acesso em: 13 jun. 2017.

HAYLES, N. Katherine. Literatura eletrônica: novos horizontes para o literário. Trad. Luciana Lhullier e Ricardo Moura Buchweitz. São Paulo: Global, Fundação Universidade de Passo Fundo, 2009.

LAJOLO, Marisa; ZILBERMAN, Regina. Literatura infantil brasileira: uma nova/ outra história. Curitiba: PUCPress, 2017.

LAJOLO, Marisa; ZILBERMAN, Regina. Literatura infantil brasileira: história \& histórias. 6. ed. São Paulo: Ática, 2007.

Livro de Monteiro Lobato é a primeira publicação interativa do iPad no Brasil. G1. São Paulo, 18 Ago. 2010. Disponível em: http:/g1.globo.com/tecnologia/noticia/2010/08/livro-de-monteiro-lobato-eprimeira-publicacao-interativa-do-ipad-no-brasil.html. Acesso em 20 out. 2017. 
MALZONI, Isabel. "Pequenos Grandes Contos de Verdade": o making-of.

Editora Caixote. 05 out. 2016. Disponível em: http://www.editoracaixote.com.br/blog/pequenos-grandes-contos-de-verdademaking-of/. Acesso em: 18 out. 2017.

NETO, Leonardo; FACCHINI, Talita. Jabuti menos concorrido em 2016. Publishnews. Rio de Janeiro, 05 ago. 2016. Disponível em: $<$ http://www.publishnews.com.br/materias/2016/08/05/jabuti-menosconcorrido-em-2016>. Acesso em 20 out. 2017.

RODRIGUES, Maria Fernanda. Poesia bate recorde de inscrição no Jabuti e digital infantil não decola. Blog Babel, O Estado de S. Paulo. Disponível em: http://cultura.estadao.com.br/blogs/babel/poesia-bate-recorde-de-inscricao-nojabuti-e-digital-infantil-nao-decola/. Acesso em 20 out. 2017.

STEINER, George. Linguagem e Silêncio: ensaios sobre a crise da palavra. São Paulo: Companhia das Letras, 1988. 361 p. Tradução de: Gilda Stuart e Felipe Rajabally.

WOLTON, Dominique. Internet, e depois?: uma teoria crítica das novas mídias. Trad. Isabel Crossetti. 3. ed. Porto Alegre: Sulina, 2012. 229 p.

ZILBERMAN, Regina. Resposta na íntegra a questão formulada por Jaqueline Conte, gravada em áudio pelas autoras. Curitiba, 23 out. 2017. Festa Literária da Biblioteca Pública do Paraná. [A pergunta encontra-se transcrita na respectiva nota de rodapé]. Site do evento: Disponível em : $<$ http://www.bpp.pr.gov.br/modules/noticias/article.php?storyid=1009>. Acesso em: 30 out. 2017.

Recebido em 30/09/2017

Aprovado em 03/12/2017 